\title{
Nova ocorrência de Poaceae para a América do Sul: Alloteropsis (Panicoideae/Poaceae)
}

Antônio Elielson Sousa da ROCHA ${ }^{1}$ \& Izildinha Souza MIRANDA²

\section{RESUMO}

Registra-se, pela primeira vez, a ocorrência de Alloteropsis J. Presl (Panicoideae/Paniceae s.l.) no Brasil (Alloteropsis cimicina (L.) Stapf), no Estado do Amapá. Este é também o primeiro registro do gênero e da espécie na América do Sul. A espécie é descrita e ilustrada. Chaves de identificação, comentários taxonômicos, observaçôes ecológicas e conservacionistas são também apresentados.

PALAVRAS-CHAVE: Gramineae, Estado do Amapá, invasoras.

\section{New occurrences of Poaceae for the South America: Alloteropsis (Panicoideae/Poaceae)}

\section{ABSTRACT}

In this paper, Alloteropsis J. Presl (Panicoideae/Paniceae s.l.) is registered for the first time in Brazil, in the State of Amapá.. This is also the first record of the genus in the South America. The species is described and illustrated. Identification keys and comments on the taxonomy, ecology and conservation are presented.

KEYWORDS: Gramineae, Amapá State, weeds. 


\section{INTRODUÇÃO}

$\mathrm{O}$ gênero Alloteropsis J. Presl pertence à tribo Paniceae s.l., Panicoideae, Poaceae (Sánchez-Ken e Clark 2010). Com ca. 3300 espécies e 206 gêneros (GPWG 2001), Panicoideae domina nas regióes tropicais e temperadas do globo, e abriga algumas das Poaceae mais importante economicamente, tais como o milho (Zea mays L.), sorgo (Sorghum bicolor (L.) Moench) e cana-de-açúcar (Saccharum officinarum L.) (Giussani et al. 2001).

Para o Brasil, Filgueiras et al. (2011) registram a ocorrência de 91 gêneros e 772 espécies Panicoideae, sendo a maioria pertencente à tribo Paniceae s.l., tipicamente tropical e caracterizada pelas espiguetas articuladas abaixo das glumas, dois antécios, o inferior estaminado ou neutro, lema glumiforme, pálea presente ou ausente; o superior frutífero, com lema e pálea menos membranosos que as glumas (Aliscioni et al. 2003).

O gênero Alloteropsis, é considerado monofilético e pertence a um clado com notável diversidade anatômica e bioquímica dentre as Paniceae, apresentando relação filogenética próxima com espécies do gênero Panicum L. do qual foi segregado (Ibrahim et al. 2009). Engloba cinco espécies, com distribuição na faixa tropical do sul da África, Índia, Sudeste Asiático e Austrália (Shouliang e Phillips 2006), sem registro conhecido para o Brasil (Filgueiras et al. 2011). Caracteriza-se por apresentar antécio fértil aristado e gluma superior ciliada (Clayton e Renvoize 1986).

Este trabalho tem por objetivo divulgar a primeira ocorrência de Alloteropsis no Brasil e na América do Sul, assim como esclarecer aspectos sobre sua morfologia, taxonomia e condiçōes ecológicas.

\section{MATERIAL E MÉTODOS}

Foram coletadas e analisadas três amostras em três diferentes fragmentos de savana nos arredores do município de Macapá, Amapá, sendo em duas delas indivíduos férteis

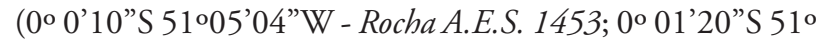
06'05"W - Rocha A.E.S. 1454 ), em uma, estéreis (0²'10" S 51 14' 17"W - Rocha A.E.S. s.n.). As coleções férteis foram depositadas no herbário MG (Museu Paraense Emílio Goeldi) e suas duplicatas serão distribuídas a herbários nacionais.

As descriçôes, chaves de identificaçóes e informaçôes sobre a distribuiçấo geográfica do gênero e da espécie foram baseadas nos trabalhos de Shouliang e Phillips (2006) e Clayton e Renvoize (1986). O material testemunho foi identificado com base em chaves analíticas eletrônicas obtidas através de Kew (2011). A ilustração da espécie, confeccionada pelo primeiro autor, restringe-se aos principais caracteres diagnósticos do taxon e está baseada somente nos materiais coletados. A terminologia adotada éa proposta por Longhi-Wagner et al. (2001).

\section{RESULTADOS E DISCUSSÃO}

A regiấo de coleta dos exemplares de Alloteropsis está localizada no estuário do rio Amazonas, a uma altitude de 16 m.s.m., apresenta vegetaçáo de savana (Sanaiotti et al., 1997), caracterizada por um estrato inferior herbáceo contínuo, com predomínio de Trachypogon spicatus (L.f.) Kuntze (Poaceae) e um estrato arbustivo e arbóreo, espaçados com predomínio de Byrsonima crassifolia (L.) Kunth (Malpighiaceae), Tabebuia caraiba (Mart.) Bureau (Bignoniaceae), Salvertia convallariodora A.St.-Hil.(Vochysiaceae) e Palicourea rigida Kunth (Rubiaceae), podendo atingir até 6 metros de altura.

O clima da regiáo é do tipo Ami, com precipitação pluviométrica média anual de $2.260 \mathrm{~mm}$, concentrada de janeiro a julho; a temperatura média é de $26^{\circ} \mathrm{C}$ e umidade relativa do ar superior a $80 \%$ (Mochiutti e Meirelles 2001). O solo da área é um latossolo amarelo de textura franco-argiloarenosa, bem drenado, de baixa fertilidade e elevada acidez (Souza Filho et al. 1986).

\section{Alloteropsis Presl, Rel. Haenk. 343. 1830.}

Plantas anuais ou perenes. Bainhas foliares glabras ou pilosas; lígula membranosa ou uma fileira de tricomas. Lâmina foliar linear a lanceolada, glabra ou pilosa. Sinflorescência composta de ramos unilaterais, digitados, alternos ou verticilados em um eixo principal; ráquis triquetra. Espiguetas ovadas a elípticas, dorsalmente comprimidas; glumas desiguais, a inferior mais curta que a espigueta, aguda a acuminada; a superior do comprimento da espigueta, com margens ciliadas; antécio inferior com flores estaminadas, lema semelhante a gluma superior, porém glabra, pálea curta e profundamente bífida; lema superior cartáceo aristado, margem estreita, cobrindo as bordas da pálea. Cariopse elíptico-oblonga.

\section{Chave para diferenciação dos gêneros mais relacionados a Alloteropsis}

1. Inflorescência em panícula típica .2

2. Pedicelo com ápice obliquo .... Tatianyx Zuloaga \& Soderstr.

2. Pedicelo com ápice truncado ... Panicum L.

1. Inflorescência em panícula de ramos unilaterais ............. 3 3 Espiguetalateralmente comprimida..... Oplismenus P. Beauv.

3. Espigueta dorsalmente comprimida................. 4 4. Lemasuperior mútico, coriáceo.....Echinochloa P. Beauv. 4. Lema superior aristado, cartáceo.........Alloteropsis J. Presl

\section{Chave para diferenciação das espécies de Alloteropsis}

1. Planta perene, lamina foliar linear a convoluta ..............2

2. Colmo fino, bainha glabra a pubescente ... A. angusta Stapf.

2. Colmo engrossado na base, bainha tomentosa ............ 3 
3. Antécio superior glabro ou esparsamente pubescente A. semialata (R.Br.) Hitchc.

3. Antécio superior papiloso..........A. papillosa Clayton

1. Planta anual, lâmina foliar lanceolada 4

4. Ramos da sinflorescência desprovidos de espiguetas na $1 / 2$ inferior A. $\operatorname{cimicina}(\mathrm{L}$.) Stapf.

4. Ramos da sinflorescência com espiguetas ao longo de toda ráquis A. paniculata (Benth.) Stapf.

Alloteropsis cimicina (L.) Stapf , Fl. Trop. Afr. 9:487. 1919.

Figura 1A-D.

Erva anual, $30-50 \mathrm{~cm}$ altura, colmo ramificados, enraizando nos nós inferiores. Nós glabros a esparsamente piloso. Bainha foliar $8-10 \mathrm{~cm}$ compr., $1 \mathrm{~mm}$ largura, pubescente; lígula membranoso-ciliada, tricomas $0,5 \mathrm{~mm}$ compr.. Lâmina foliar lanceolada, pubescente, base cordada, ápice acuminado, 5-10 cm compr., 0,5-1 cm largura; Sinflorescência terminal, pedúnculo alongado, $20-25 \mathrm{~cm}$ compr., ramos 5-9, verticilados, 10-18 cm compr.; desprovidos de espiguetas na $1 \frac{1}{2}$ inferior; ráquis híspida, estreita. Pedicelos desiguais, $1-2 \mathrm{~cm}$ comprimento. Espiguetas pareadas, ovadas a elípticas, dorsalmente comprimidas; glumas desiguais, a inferior ovada, $2 \mathrm{~mm}$ compr., $1 \mathrm{~mm}$ largura, acuminada, dorso levemente pubescente, 3-nervada, gluma superior pouco mais longa que o antécio superior, 2,5 $\mathrm{mm}$ compr., 1,2 mm largura, 5-nervada, margem ciliada; antécio inferior com flor masculina, lema membranoso, piloso no ápice, 2,3 $\mathrm{mm}$ compr., $1 \mathrm{~mm}$ largura, agudo, antécio superior com flor bissexuada, cartáceo, estramíneo, $2 \mathrm{~mm}$ compr., $1 \mathrm{~mm}$ largura; lema liso, envolvendo a pálea, 3-nervado, arista 1,8$2 \mathrm{~mm}$ compr., escabrosa; pálea papilosa, plana. Estame 3. Cariopse não vista.

Material examinado: Brasil. Amapá: Macapá, 00 0'10"S 5105'04"W, 5/VII/2010, Rocha A.E.S. 1453 (MG). Idem, 0 01'20"S 51'06'05” W, Rocha A.E.S. 1454 (MG).

Alloteropsis cimicina é uma das espécies de maior distribuição do gênero. Ocorre ao longo de toda faixa tropical no Velho Mundo, é introduzida no sul dos Estados Unidos (Zuloaga e Morrone 2003).

As coleções Rocha 1453 e 1454 (MG) são provenientes de pequenas populaçóes que margeiam encraves de savanas, na área urbana e nos arredores da cidade de Macapá. Apresentam os caracteres diagnósticos de $A$. cimicina: lâmina foliar lanceolada, ramos da sinflorescência verticilados com metade inferior desprovida de espiguetas.

Os primeiros propágulos de Alloteropsis cimicina provavelmente chegaram ao Brasil juntamente com sementes de eucalipto (Eucalyptus spp.), de origem australiana introduzidas no estado do Amapá como opção econômica

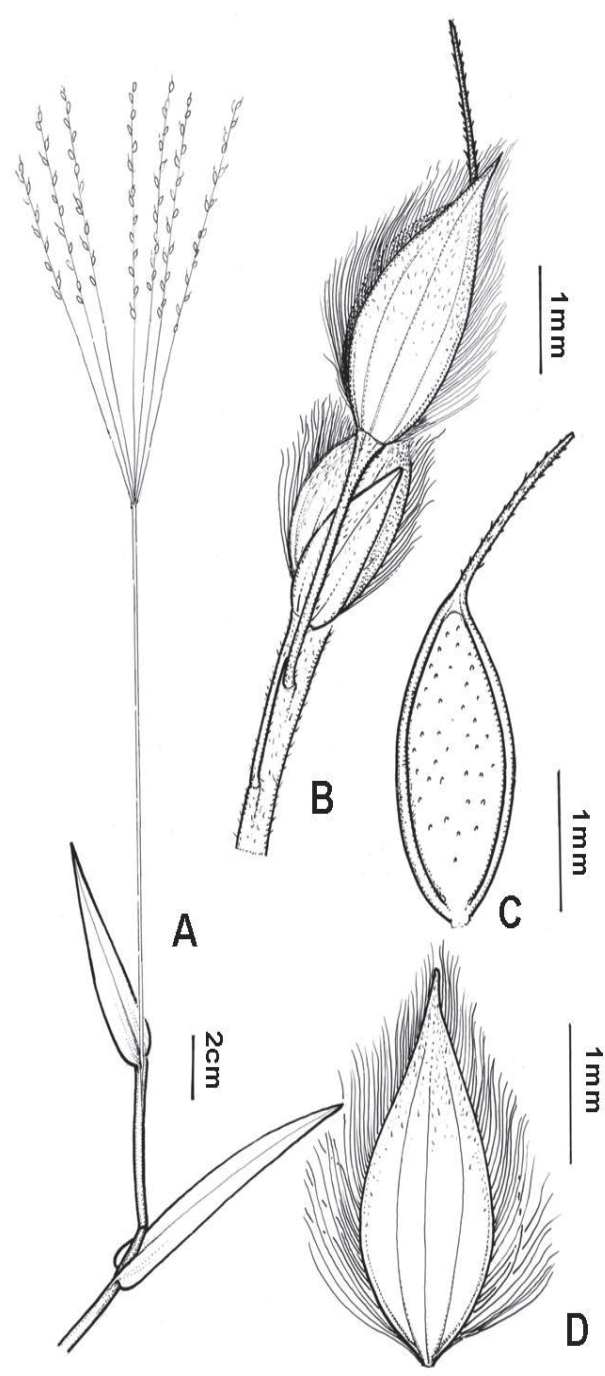

Figura 1. A - D. Alloteropsis cimicina (Linn.) Stapf: A. Fragmento de um ramo florífero da planta; B. Espiguetas; C. Antécio fértil com arista; D. Gluma superior com margens ciliadas. (Baseado em Rocha, 1453 - MG).

para uso madeireiro. Os plantios comerciais com eucalipto foram estabelecidos preferencialmente na faixa de savana, na costa atlântica do estado, onde $A$. cimicina foi coletada e provavelmente está se disseminando a partir destas localidades.

As espécies de Alloteropsis, devido à enorme eficiência fotossintética, são consideradas grandes competidoras em sua região de origem (Ueno e Sentoku 2006; Brown e Hattersley 1989). Portanto, apesar de ainda apresentar populaçóes com poucos indivíduos dispersos, margeando fragmentos de savanas, $A$. cimicina pode se transformar em futura ameaça às savanas amazônicas, da mesma forma como vem ocorrendo em outras áreas de savanas da América do Sul, onde outras 
espécies exóticas estão se tornando invasoras e ameaçando a biodiversidade local (Pivello et al. 1999).

\section{AGRADECIMENTOS}

Ao Dr. Francisco Valls da EMBRAPA- CENARGEN e ao

Editor e revisores anônimos pelas valiosas sugestóes.

\section{BIBLIOGRAFIA CITADA}

Aliscioni, S.S.; Giussani, L.M.; Zuloaga, F.O.; Kellogg, E.A. 2003. A molecular phylogeny of Panicum (Poaceae:Paniceae). Test of monophyly and phylogenetic placement with the Panicoideae. American Journal of Botany 90(5): 796-821.

Brown R.H.; Hattersley P.W. 1989. Leaf anatomy of C3-C4 species as related to evolution of C4 photosynthesis. Plant Physiology, 91: 1543-1550.

Clayton, W. D.; Renvoize, S. A. 1986. Genera Graminum. Royal Botanic Gardens, London. 389 pp.

Filgueiras, T. S. et al. 2011. Poaceae in Lista de Espécies da Flora do Brasil. Jardim Botânico do Rio de Janeiro. Disponível em: http://floradobrasil.jbrj.gov.br/2011>. Acesso em 15 out. 2011.

Giussani, L.M.; Cota-Sánchez, J.H.; Zuloaga, F.O.; Kellogg, E.A. 2001. A molecular phylogeny of the grass subfamily Panicoideae (Poaceae) shows multiple origins of C4 photosynthesis. American Journal of Botany, 88: 1993-2012.

GPWG (Grass Phylogeny Working Group). 2001. Phylogeny and subfamilial classification of the grasses (Poaceae). Annals Missouri Botanical Garden 88 (3): 373-457.

Ibrahim, D. G.; Burkel, T.; Ripley, B.S.; Osbomel, C.P. 2009. A molecular phylogeny of the genus Alloteropsis (Panicoideae, Poaceae) suggests an evolutionary reversion from $\mathrm{C}_{4}$ to $\mathrm{C}_{3}$ photosynthesis. Annals of Botany, 103 (1): 127-136.
Kew Royal Botanical Garden. 2011. Flora Zambesiaca. (http://apps. kew.org/efloras/key.do). Acesso em 10/01/2011.

Longhi-Wagner, H.M; Bittrich, V.; Wanderley, M.G.L.; Shepherd, G.J. 2001. Poaceae. Flora Fanerogâmica do Estado de São Paulo, 1: 1-291.

Mochiutti, S.; Meirelles, P.R.L. 2001. Efeitos do pastejo sobre a composição botânica e produção de uma pastagem nativa de cerrado do Amapá. Embrapa Amapá. Boletim de Pesquisa e Desenvolvimento, 46: 1-10.

Ueno, O.; Sentoku, N. 2006 Comparison of leaf structure and photosynthetic characteristics of C3 and C4 Alloteropsis semialata subspecies. Plant, Cell and Environment, 29: 257-268.

Pivello, V.R.; Carvalho, V.M.C; Lopes, P.F.; Peccinini, A.A.; Rosso, S. 1999. Abundance and distribution of native alien grasses in a "Cerrado". (Brazilian Savanna) Biological Reserve. Biotropica, 31: 71-82.

Sanaiotti T., Bridgewater S. and Ratter J.A. 1997. A floristic study of the savanna vegetation of the state of Amapá, Brazil, and suggestions for its conservation. Boletim Museu Paraense Emílio Goeldi, Série Botaânica 13: 3-29.

Sánchez-Ken, J.G.; Clark, L.G. 2010. Phylogeny and a new tribal classification of the Panicoideae s.l. (Poaceae) based on plastid and nuclear sequence data and structural data. American Journal of Botany. 97(10): 1732-1748.

Shouliang, C.; Phillips, S.M. 2006. Alloteropsis Presl, Flora of China, 22: 519-520.

Souza Filho, A. P. da S.; Pimentel, D. M.; Meirelles, P. R. de L. 1986. Manejo de pastagens nativas de área de cerrado do Amapá com o uso de fogo. Macapá: Embrapa-UEPAT de Macapá. 4 p.

Zuloaga, F.O.; Morrone, O. 2003. Alloteropsis. P. 16. In: R.J. Soreng \& S.J. Pennington (eds.). Catalogue of New World Grasses (Poaceae): III. Subfamilies Panicoideae, Aristidoideae, Arundinoideae and Danthonioideae. v.46. Washington, Smithsonian Institution.

Recebido em : 23/08/2011

Aceito em : 11/12/2011 